\title{
Limitações da docência remota: discurso do sujeito coletivo
}

\author{
Errol Fernando Zepka Pereira Junior ${ }^{1}$ \\ Tanise Paula Novello ${ }^{2}$ \\ Fabrine Diniz Pereira ${ }^{3}$ \\ Pedro Antônio de Melo ${ }^{4}$ \\ Nathalia Fehlberg Ribeiro Zepka ${ }^{5}$
}

\section{RESUMO}

Tendo em vista a resposta adaptativa que ambientes educacionais precisaram ter em função da demanda gerada pela Covid-19, este estudo tem como objetivo compreender as potencialidades e desafios do trabalho remoto à luz da lente teórica das limitações digitais. Para isso, foram realizadas entrevistas com professores, especialistas em Educação a Distância, que já coordenaram projetos nesta área em suas instituições, analisando as falas sob a técnica do Discurso do Sujeito Coletivo (DSC). Com o DSC foi possível perceber que as limitações de acesso apontadas pelos professores estão relacionadas à ausência de artefatos apropriados e/ou a dificuldades em configurá-los. Além disso, outras questões foram apontadas, como: falta de mobiliário e ambiente apropriados; o impacto do trabalho remoto e os desafios em alinhá-lo à rotina da família; a falta de infraestrutura adequada e estabelecimento de espaços apropriados para o diálogo e o desenvolvimento das atividades laborais.

Palavras-chave: Limitações digitais. Covid-19. Potencialidades. Ensino remoto.

\footnotetext{
${ }^{1}$ zepkaef@gmail.com - Universidade Federal de Santa Catarina

2 tanisenovello@hotmail.com - Universidade Federal de Pelotas

3 fabrinediniz@hotmail.com - Universidade Federal de Rio Grande

${ }^{4}$ pedro.inpeau@gmail.com - Universidade Federal de Santa Catarina

${ }^{5}$ nathaliazepka@gmail.com - Universidade Federal de Rio Grande
} 


\title{
Limitations of remote teaching: collective subject speech
}

\begin{abstract}
Considering the adaptive response that educational environments needed to have, due to the demand generated by Covid-19, this study aims to understand the potential and challenges of remote work in light of the theoretical lens of digital limitations. Interviews were conducted with specialist professors in distance education who have already coordinated projects in this area in their institutions, analyzing their speeches using the technique of the Discourse of the Collective Subject (DSC). The DSC allowed us to realize that the access limitations pointed out by the teachers are in line with the absence of appropriate artifacts and/or difficulties in configuring them, in addition, ergometric issues such as appropriate furniture and environment were also pointed out and the impact of remote work in the routine and family experiences and challenges in aligning work demands, in addition to the lack of other educational agents such as adequate infrastructure and establishment of appropriate spaces for dialogue and the development of work activities.
\end{abstract}

Keywords: Digital limitations. Covid-19. Potentialities. Remote teaching. 
A Covid-19 é uma doença que foi identificada pela primeira vez em 2019 na cidade de Wuhan, província de Hubei na China, e reconhecida pela Organização Mundial da Saúde (OMS) em 31 de dezembro do mesmo ano. Essa doença gerou uma pandemia e assustou o mundo por meio da divulgação através dos noticiários, que alertavam sobre o perigo, riscos de contágio e formas de prevenção. Todavia, a Covid-19 não foi levada a sério como deveria e acabou por se espalhar rapidamente por todo o mundo, acarretando diversos problemas de saúde, econômicos e sociais (MARIVATE; COMBRINK, 2020). Nesse sentido, Spinelli e Pellino (2020) destacam que foram diversos os impactos dos desdobramentos da pandemia, refletindo diretamente na economia e educação.

Nicola et al. (2020) relatam que, como ainda não existiam vacinas para controlar a propagação do vírus nem medidas farmacêuticas para mitigar os problemas de saúde gerados pela Covid-19, novas providências precisaram ser adotadas para que se pudesse retardar a proliferação da doença. O meio encontrado foi a imposição do fechamento dos espaços de convivência que gerassem aglomerações, o que instituiu rígidas normas de isolamento social.

Esse novo cenário emergencial estendeu-se aos diversos âmbitos da sociedade, incluindo os ambientes de trabalho, sociais e educacionais. Nesse sentido, Arruda (2020) explica que o âmbito da educação presencial aparece como um dos potencializadores de transmissão do vírus, uma vez que a heterogeneidade de pessoas que frequentam esses espaços torna os ambientes ainda mais propícios para a propagação de doenças. Além disso, o autor acrescenta que esses ambientes estão constituídos de pessoas pertencentes a zonas de vulnerabilidade, com pouco acesso às formas básicas de prevenção, como a própria questão do isolamento, por precisarem trabalhar, por exemplo.

Em uma pesquisa realizada pelo instituto DataSenado entre os dias 24 e 28 de julho de 2020 , foram entrevistados por telefone 2,4 mil brasileiros com idade de 16 anos ou mais, sendo que a análise dos dados considerou dois grupos: pais que têm filhos que frequentam escola ou faculdade, e participantes da pesquisa que são alunos de escolas ou faculdades. Os resultados apresentaram que, dos quase 56 milhões de alunos matriculados na Educação Básica e Superior no Brasil, aproximadamente 35\%, o que corresponde a 19,5 milhões, tiveram as aulas suspensas devido à pandemia da Covid-19, enquanto 58\%, ou 32,4 milhões, passaram a ter aulas remotas. Na rede pública, $26 \%$ dos alunos que estão tendo aulas on-line não possuem acesso à internet (CHAGAS, 2020).

Outra pesquisa, desenvolvida pelo Instituto Península (2020), intitulada Sentimento e Percepção dos professores brasileiros nos diferentes estágios do Coronavírus no Brasil, ouviu 7.734 mil professores de todo o país entre os dias 13 de abril e 14 de maio de 2020, no início do isolamento social, e depois em julho. A conclusão foi que $83 \%$ dos professores brasileiros não se sentem preparados para o Ensino Remoto; e 88\% revelaram ter dado a primeira aula virtual após a pandemia. Por isso, ao passo que as instituições de ensino estão buscando novas estratégias para oferecer educação sem perda de qualidade, estas parecem estar diante de um cenário complexo a ser gerido: parte de seus professores não sabem operar o processo de ensinar e 
aprender de maneira on-line, que demanda outras dinâmicas metodológicas e relações interpessoais.

Nesse panorama, torna-se necessária a adaptação dos professores para um novo modelo educacional que responda de forma efetiva ao "novo normal", bem como o entendimento das potencialidades dos ambientes virtuais de aprendizagem e das limitações de acesso que possam estar imbuídas nesse contexto. Assim, o presente estudo visa compreender as potencialidades e desafios do trabalho remoto à luz da lente teórica das limitações digitais de Bellini, Giebelen e Casali (2010), por meio da técnica de análise do Discurso do Sujeito Coletivo.

\section{EMBASAMENTO TEÓRICO}

A fim de elucidar os tipos de educação não presencial, faz-se necessária a distinção entre os aspectos que se pretende analisar. Alguns estão envolvidos com outros, todavia, para esta pesquisa a intenção é tratar esses modelos em quatro tipos, a saber: (i) A Educação a Distância (EaD); (ii) A Educação Presencial apoiada pelas tecnologias digitais da informação e comunicação (TDICs); (iii) A Educação Presencial com $20 \%$ de sua operacionalização a distância; e (iv) A Educação Emergencial Remota.

Na próxima seção, serão discutidos os tipos de educação não presencial, bem como as limitações digitais e de acesso. Na sequência, serão apresentadas algumas especificações sobre a educação não presencial em períodos de pandemia da Covid-19, e, por fim, serão exibidos e discutidos estudos anteriores acerca de limitações digitais dos professores na pandemia da Covid-19.

\subsection{Tipos de educação não presencial}

O formato educacional não presencial discutido apresenta-se como sendo a Educação Presencial apoiada pelas TIC. Rapanta et al. (2020) explicam que a redução de custo dos artefatos tecnológicos e a crescente expansão de acesso à internet tem tocado a Educação Presencial, sugerindo algumas adequações aos formatos mais tradicionais para essa utilização de tecnologia nas aulas. Para os autores, a maior parte das IES dispõe de uma extensa rede de computadores com acesso à internet, pontos de acesso à internet - como o wireless - e outros. Essas aparelhagens passaram a ser incorporadas à cultura do Ensino Presencial, tornando-se ferramentas paralelas através dos ambientes de ensino e aprendizagem, operados por meio dos Ambientes Virtuais de Aprendizagem (AVA).

Miranda (2007) aponta que não é recente a incorporação de TDICs, uma vez que o ensino formal vem incluindo diversos apoios externos na operacionalização das aulas, como a indicação de livros não didáticos e exibição de filmes nas salas de aula. Nesse sentido, a internet aparece como uma unificação desses esforços, permitindo a organização dos materiais em um único ambiente, em que os atores da educação possam transpor parte do que acontece no mundo físico para o mundo digital, permitindo o melhor uso do espaço e tempo físico para atividades em que é necessária essa configuração, como atividades práticas. 
Imerso nesse modelo híbrido, o docente precisa seguir comunicando-se com os discentes de forma presencial e também on-line. Moran (2015) explica que essa mescla entre sala de aula e ambiente virtual é fundamental para o processo educacional acontecer de forma efetiva em tempos de tanta destreza digital, por parte dos discentes. Através de práticas, atividades, jogos e construção de projetos no formato on-line, os estudantes podem fazer uma combinação entre aprender junto com os colegas e professores.

Gomes (2018) traça um desenvolvimento temporal para explicar a possibilidade de adesão de $20 \%$ de EaD para os cursos presenciais. A autora apresenta que a primeira publicação que regulamentou o acoplamento entre a Educação Presencial e a EaD no Ensino Superior foi a Portaria 2.253/2001, esta concretizou o objetivo do MEC de acelerar a implementação da EaD nos cursos de graduação presenciais.

Todavia, ainda de forma tímida, a portaria permitia a oferta experimental de $20 \%$ EaD só nos cursos que já tivessem seu reconhecimento junto ao MEC. Além de abrir a possibilidade, a portaria delimitou que a oferta de EaD nos cursos presenciais não poderia ultrapassar os $20 \%$ para a integralização do currículo desses cursos. Além disso, as disciplinas que fossem oferecidas nesses 20\% deveriam também ser oferecidas no formato presencial, e apenas as Universidades e Centros universitários poderiam aderir aos 20\% (GOMES, 2018).

A autora explica, ainda, que em 2004, já em um novo governo, foi publicada a Portaria $4.059 / 2004$, em que a implementação dos $20 \%$ se ampliou consideravelmente entre as IES, uma vez que a exigência de ofertar as disciplinas no formato presencial e não presencial - o que gerava mais custos às IES - foi excluída. Além disso, todas as IES poderiam articular esses $20 \%$, cabendo apenas a exigência de solicitar essa liberação junto ao MEC.

Avançando na discussão, Gomes (2018) acrescenta que foi em 2016, com a publicação da Portaria 1.134/2016, o aumento da autonomia das IES para implementar os $20 \%$ na integralização de seus cursos, visto que as IES com pelo menos um curso de graduação reconhecido pelo MEC pode incluir, na organização pedagógica e curricular de seus cursos de graduação presenciais regularmente autorizados, a oferta de disciplinas na modalidade a distância, respeitando a exigência de não ultrapassar os $20 \%$.

Devido à pandemia da Covid-19, as IES precisaram tomar decisões rápidas sobre um plano para dar continuidade às atividades em um formato não presencial. Arruda (2020) explica que há uma confusão nas denominações do modelo, chamadas de Educação on-line, Educação a distância ou mesmo Educação Remota. Para o autor, apesar de serem colocados como sinônimos, os termos são diferentes. Ao passo que a Educação a Distância pressupõe o formato como um meio em si mesmo, a Educação Remota vem a ser uma resposta rápida e elaborada emergencialmente para o período pandêmico.

A EaD, enquanto modalidade, dispõe de regulamentação específica, definindo diretrizes para sua operacionalização. $\mathrm{Na} \mathrm{EaD}$, várias metodologias podem ser utilizadas, como o uso de sistemas on-line, de forma síncrona - o que pode ser chamado de educação on-line. Mas, também a utilização de ferramentas assíncronas e analógicas, como os materiais impressos (ARRUDA, 2020). A EaD caracteriza-se por todo um arcabouço de TDICs, legislações e atores que permitem a operacionalização do processo de ensino-aprendizagem acontecer todo em si mesmo, sem a presença física de seus atores. 
Assim, a Educação Remota aparece como uma terceira via que, segundo Hodges et al. (2020), aparece no movimento feito no caráter emergencial em apropriar-se de TDIC sem circunstâncias específicas para atender um público que outrora operava em um formato presencial. A EaD envolve um planejamento anterior, considerações sobre os perfis de docentes e discentes, desenvolvimento a médio e longo prazo de estratégias de ensino-aprendizagem que possibilitem as interações síncronas e assíncronas, o envolvimento de diversos profissionais que contribuam com o desenvolvimento da prática pedagógica com qualidade (MAIA; MATTAR, 2008).

A Educação Remota Emergencial aparece como uma mudança temporária de se trabalhar os conteúdos curriculares antes presenciais para um formato alternativo em resposta à uma crise. Esse novo formato faz uma combinação entre práticas dos modelos presenciais e EaD; além disso, objetiva manter-se assim pelo tempo que a crise sanitária da Covid-19 durar (HODGES et al., 2020). A Educação Remota pode ser apresentada como semelhante à Presencial, com práticas como a transmissão das aulas no mesmo período em que aconteceriam as aulas presenciais. Ademais, com essa semelhança ao modelo presencial, a Educação Remota avança em alguns pressupostos do modelo EaD ao implementar ferramentas assíncronas de comunicação, como fóruns de discussão - sem contar a ampla utilização de aulas gravadas e disponibilizadas para acesso posterior.

\subsection{Limitações digitais}

A Pesquisa Nacional por Amostra de Domicílios Contínua - Tecnologia da Informação e Comunicação, divulgada recentemente pelo Instituto Brasileiro de Geografia e Estatística (IBGE), mostra que uma em cada quatro pessoas no Brasil não tem acesso à internet. Em números totais, isso representa cerca de 46 milhões de brasileiros que não acessam a rede (TOKARNIA, 2020). Os dados que se referem aos três últimos meses de 2018 mostram que o percentual de brasileiros com acesso à internet aumentou no país de 2017 para 2018, passando de 69,8\% para 74,7\%, mas que 25,3\% ainda estão sem acesso. Em áreas rurais, o índice de pessoas sem acesso é maior que nas cidades, chegando a 53,5\%; já em áreas urbanas é de 20,6\% (TOKARNIA, 2020). Outro dado retratado por essa pesquisa foi que $56 \%$ das pessoas que usam a internet diariamente fazem isso por meio de aparelhos celulares, o que pode ser um indicativo de não possuírem um notebook ou computador pessoal em casa.

Em tal contexto, recorre-se ao conceito de Limitações Digitais de Bellini, Giebelen e Casali (2010), que se configura em uma nova forma de abordar a exclusão e a desigualdade digital, compreendendo limitações de restrições individuais em nível de acesso material e social às TDICs, habilidades e competências necessárias para utilizá-las.

As teorias sobre Limitação Digital iniciaram em 1986 com os estudos de Barras, seguidos dos de Van Dijk e Hacker (2003), Klecun (2008), Bellini (2018), Bellini, Giebelen e Casali (2010) e Bellini et al. (2012, 2016), que ampliaram o conceito de Limitação Digital. No presente estudo, o enfoque será na lente teórica do estudo de Bellini e colaboradores (BELLINI; GIEBELEN; CASALI, 2010) que mais recentemente apresentaram a Limitação Digital a partir de três dimensões: a limitação de acesso, a limitação cognitivo-informacional e a limitação comportamental.

A limitação de acesso refere-se às dificuldades sociais e materiais do indivíduo em usar as TIC. A limitação cognitivo-informacional diz respeito às deficiências do indivíduo em relação às 
habilidades digitais necessárias para utilizar de forma efetiva a TIC. Por fim, a limitação comportamental corresponde à dificuldade do indivíduo em aplicar as suas habilidades digitais, ainda que as possua em nível elevado. Os autores observam que, neste último tipo de limitação, pode ocorrer o uso intensivo, mas inadequado, expondo "um fenômeno sutil e grave" (BELLINI; GIEBELEN; CASALI, 2010, p. 31) relacionado à efetividade do uso das TIC.

Ao apresentar o modelo com as três formas principais de Limitação Digital e suas interdependências, os autores dialogam com fundamentos presentes na teoria do comportamento planejado. As relações entre as formas de Limitação Digital representam caminhos que seguem sequências cronológicas ou sequências causais, dependendo do caso. Em outras palavras, sem antes superar as limitações sociais ou materiais de acesso às TIC, não faz sentido avançar sobre as limitações de habilidades potenciais e comportamentais do indivíduo para um uso efetivo dessas TDICs. Similarmente, sob uma perspectiva causal, a ocorrência de condições insatisfatórias de acesso pode estimular comportamentos contrários ao uso previsto para a tecnologia, bem como impeditivos cognitivos.

No que diz respeito às causas das limitações de acesso, Agarwal, Animesh e Prasad (2009) destacam que, mesmo o acesso sendo resultado de escolhas individuais, o acesso contínuo à internet está sujeito à influência social que emana da proximidade geográfica e de interações com outros indivíduos que já acessam. Para Dwivedi e Irani (2009), uma das variáveis mais importantes é, justamente, a influência social. Neste sentido, Willis e Tranter (2006) enfatizam que as variáveis demográficas vêm se tornando menos importantes para a pesquisa, sendo substituídas por questões relativas à influência social. Bellini et al. (2012) explicam que na literatura percebe-se a utilização rotineira de alguns termos para tratar a dificuldade de acesso e o uso não efetivo de TIC, entre os quais se destacam "exclusão digital" - visão dicotômica sobre acesso e não-acesso à TIC - e "desigualdade digital" - visão comparativa entre indivíduos quanto ao acesso à TIC. Ainda nesse estudo, os autores entendem que as limitações de acesso são as dificuldades sociais e materiais de um indivíduo para acessar as TDICs, resultado de restrições econômicas, falta de acesso voluntário, inadequação dos recursos tecnológicos disponíveis, interfaces homemmáquina de baixa ergonomia, ambientes de uso insalubres e outros fatores.

Já em uma nova pesquisa na mesma temática, Bellini (2018) expande a discussão sobre limitações de acesso ao explicar que essa primeira dimensão em que se mede a ocorrência de limitações digitais refere-se às barreiras sociais, materiais e contextuais para acessar e usar adequadamente as TIC nos processos de informação e comunicação. Os autores explicam que as limitações de acesso se manifestam através dos níveis de exclusão social, da falta de acesso à Internet e largura de banda desejável, de hardware e software obsoletos, de interfaces homemcomputador mal projetadas e móveis de escritório, de tempo insuficiente para realizar as tarefas no computador, além de outros fatores.

Arruda (2020) entende que o isolamento social transformou o modo de vida com o qual as pessoas estavam habitualmente acostumadas, gerando desconstruções sociais em diversos aspectos, mas principalmente na área da educação, o que tornou necessário um repensar quanto às formas de ensinar e aprender. Em consonância, Hodges et al. (2020) acrescentam que a Educação Remota, em tempos de pandemia, surge como uma mudança temporária na educação, 
e que posteriormente as aulas tendem a retornar ao modelo presencial, porém transformadas pela combinação do antigo normal e do novo normal, com amparo das TIC.

Pereira Junior, Paes e Ribeiro (2020) apresentam que as experiências de vida dos professores, bem como a vivência familiar, socialização no período de formação escolar, integração na comunidade em que vivem, entre outros, influenciam esses sujeitos na escolha da profissão e na forma como atuam na profissão. A exemplo disso, pode-se afirmar que o background - antecedentes pessoais - dos professores os influencia na escolha da abordagem pedagógica que adotam, na maneira como se relacionam com os alunos e na forma como os avaliam.

Novello, Pereira Junior e Ribeiro (2020), em seus estudos, objetivaram compreender, através das percepções de professores, as limitações digitais que aparecem como dificultadoras para a utilização das TDICs durante o período de trabalho remoto ocasionado pela pandemia da Covid-19. Os autores realizaram uma pesquisa diagnóstica, exploratória e qualitativa, por meio de entrevistas com 14 professores que são pesquisadores especialistas na área da Educação a Distância. A partir da análise dos registros das entrevistas, identificou-se 90 limitações digitais que foram organizadas conforme as 3 dimensões já mencionadas.

Em limitações de acesso, os autores levantaram 49 limitações, elencadas em 2 eixos de análise: um para fatores sociais e outro para materiais. Em fatores sociais, foram levantadas 25 limitações, listadas em 2 subcategorias, a saber: integração entre as funcionalidades do AVA para os usos da docência; e problemas de configuração dos AVA. Avançando nas discussões sobre limitações de acesso, os entrevistados foram consultados a fim de discorrerem sobre as limitações materiais. Acerca destas, obteve-se 24 limitações, elencadas em 4 subcategorias: indisponibilidades do sistema; problemas com a internet; hardware, dispositivos; aspectos ergonômicos e infraestruturais. A seguir, na figura 1, apresenta-se o resumo das limitações de acesso apresentadas no estudo.

\section{Figura 1: Limitações de acesso dos professores durante a pandemia da Covid-19}

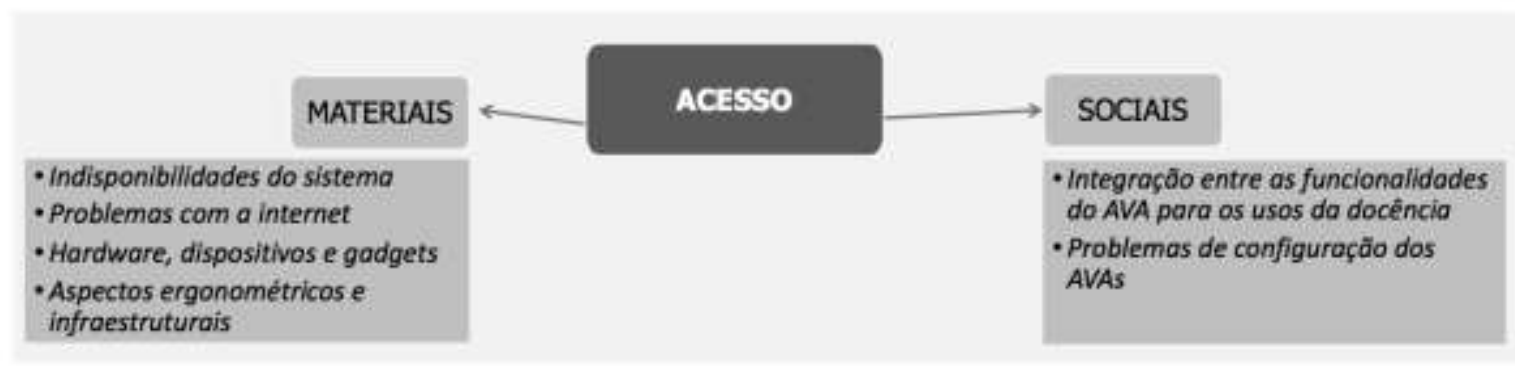

Fonte: adaptado de Novello, Pereira Junior e Ribeiro (2020).

Em seguida, serão apresentadas as escolhas metodológicas que balizaram a pesquisa, abarcando colaboradores da pesquisa, a produção de registros e método de análise desses. 
Nesta seção, descreve-se o método de pesquisa utilizado para a produção e análise dos registros produzidos durante o estudo. Nesse sentido, será apresentado o roteiro que balizou as entrevistas, o perfil dos participantes, a explicação da técnica de análise do Discurso do Sujeito Coletivo e, por fim, a análise do discurso elaborado a partir do operar das técnicas, entremeada a teóricos que permitem explicar o discurso.

\subsection{Colaboradores e roteiro}

Para esta coleta de dados, foi elaborado um roteiro de entrevista semiestruturado com doze perguntas abertas, a fim de guiar os pesquisadores durante as entrevistas. Este instrumento foi elaborado baseando-se em questões definidas nos trabalhos de Bellini (2018); Bellini, Giebelen e Casali (2010); Bellini et al. (2012; 2016); e Pereira Junior, Schroeder e Dolci (2018; 2019). A seguir, no quadro 1 , estas podem ser conferidas.

\section{Quadro 1: Roteiro de entrevistas}

\begin{tabular}{|c|c|c|}
\hline \multicolumn{2}{|c|}{$\begin{array}{c}\text { Eixo de } \\
\text { pesquisa } \\
\text { (Limitação) }\end{array}$} & Perguntas \\
\hline \multirow[b]{2}{*}{ 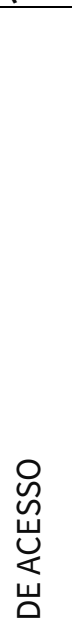 } & $\cdot \frac{n}{\frac{\pi}{U}}$ & $\begin{array}{l}\text { Qual ferramenta você usa / usou como AVA? } \\
\text { Desde quando utiliza esta ferramenta? } \\
\text { Você se sente íntimo com a ferramenta? } \\
\text { Você está integrado com o as funcionalidades dessa ferramenta para os usos da } \\
\text { docência? } \\
\text { Participou de reuniões sobre essa plataforma / seu uso? } \\
\text { Tem acesso ao que é decidido nessas reuniões? } \\
\text { Você já se sentiu impossibilidade de dar seguimento nas atividades, pois faltou } \\
\text { alguma informação ou articulação que alguém deveria ter inserido nesta plataforma? }\end{array}$ \\
\hline & $\frac{\frac{n}{\pi}}{\frac{\pi}{d}} \frac{\pi}{\frac{\pi}{\pi}}$ & $\begin{array}{l}\text { Já encontrou alguma dificuldade de acesso? } \\
\text { Quanto a qualidade da internet? } \\
\text { A disponibilidade do sistema? } \\
\text { Capacidade e rapidez do computador? } \\
\text { Tem condições ergonômicas para a realização do trabalho? }\end{array}$ \\
\hline
\end{tabular}

Fonte: elaborado pelos autores com base nos dados da pesquisa (2020).

Para definição dos participantes de pesquisa, optou-se por entrevistar pesquisadores especialistas ligados à área de Educação a Distância de universidades federais e privadas, agentes consultores de equipes multidisciplinares e professores da área de educação, com estudos publicados em periódicos indexados na listagem qualis 2019 entre A2 e B3, sobre a temática. Para isso, foram consultadas na base Sucupira as pesquisas sobre Educação a Distância publicadas nos anos de 2019 e 2020. Na sequência, esses participantes foram convidados por e-mail a participar da pesquisa, atendendo os pesquisadores no formato da entrevista. No total, dos 77 especialistas convidados, participaram 14 profissionais.

As entrevistas foram realizadas entre os dias 09 e 19 de junho de 2020 e gravadas em vídeo e áudio por meio de plataformas virtuais para videochamada, a saber: Google Meet; Hangouts; 
Skype; e Webconf, com duração aproximada de uma hora e meia. Os dados gravados - com permissão dos entrevistados -, foram transcritos e posteriormente analisados a partir dos construtos teóricos propostos nesta pesquisa. Destaca-se que anteriormente a realização da entrevista os colaboradores foram informados sobre o objetivo da pesquisa e garantido-lhes o anonimato, assim como o uso das informações somente para fins de pesquisa científica. Da mesma forma, salientou-se que poderiam a qualquer momento interromper a entrevista e/ou não responder qualquer questão, contudo esse fato não ocorreu. Assim, todos os colaboradores declararam aceite em participar, bem como o uso das informações para fins de pesquisa.

\subsection{Análise do perfil dos entrevistados}

No quadro 2 abaixo, é apresentado o perfil dos entrevistados, organizado por ordem de participação - data da realização da entrevista. Destaca-se que não foi feita a flexibilização do gênero dos entrevistados para manter o anonimato.

Quadro 2 - Perfil dos entrevistados

\begin{tabular}{|c|c|c|c|c|}
\hline ID & Formação / Titulação & $\begin{array}{l}\text { Tempo na } \\
\text { docência* }\end{array}$ & Modalidade ${ }^{\star *}$ & Instituição *** \\
\hline $\operatorname{Esp}(1)$ & $\begin{array}{l}\text { Bacharelado em Ciências Contábeis; } \\
\text { Especialização em Gestão Fiscal e } \\
\text { Planejamento Tributário e Mestrado em } \\
\text { Ciências Ambientais. }\end{array}$ & 7 anos. & $\begin{array}{l}\text { Presencial e } \\
\text { EaD. }\end{array}$ & Privada. \\
\hline $\operatorname{Esp}(2)$ & $\begin{array}{l}\text { Bacharelado em Ciência da Computação; } \\
\text { Especialização em Novas Tecnologias } \\
\text { Educacionais; Mestrado em Engenharia de } \\
\text { Teleinformática e Doutorado em } \\
\text { Engenharia Elétrica e Computação. }\end{array}$ & 13 anos. & $\begin{array}{l}\text { Presencial } \\
\text { EaD. }\end{array}$ & Pública. \\
\hline Esp (3) & $\begin{array}{l}\text { Bacharelado em Psicologia; Especialização } \\
\text { em Psicomotricidade, Educação e } \\
\text { Aprendizagem; Especialização em } \\
\text { Educação a Distância e Mestrado em } \\
\text { Psicologia. }\end{array}$ & 4 anos. & Presencial. & Privada. \\
\hline Esp (4) & $\begin{array}{l}\text { Bacharelado em Administração com Gestão } \\
\text { da Informaçãa; Mestrado em Administração } \\
\text { Estratégica e Doutorado em } \\
\text { Desenvolvimento Regional e Urbano. }\end{array}$ & 11 anos. & $\begin{array}{l}\text { Presencial e } \\
\text { EaD. }\end{array}$ & $\begin{array}{l}\text { Pública } \\
\text { Privada. }\end{array}$ \\
\hline $\operatorname{Esp}(5)$ & $\begin{array}{l}\text { Bacharelado em Informática e Mestrado em } \\
\text { Estudos Avançados em Informática. }\end{array}$ & 13 anos. & $\begin{array}{l}\text { Presencial e } \\
\text { EaD. }\end{array}$ & Pública. \\
\hline $\operatorname{Esp}(6)$ & $\begin{array}{l}\text { Bacharelado em Engenharia Química; } \\
\text { Especialização em Metodologia do Ensino } \\
\text { Superior; Especialização em Informática na } \\
\text { Educação; Mestrado em Ciência da }\end{array}$ & 40 anos. & $\begin{array}{l}\text { Presencial, } \\
\text { EaD e Híbrido. }\end{array}$ & Pública. \\
\hline
\end{tabular}




\begin{tabular}{|c|c|c|c|c|}
\hline ID & Formação / Titulação & $\begin{array}{l}\text { Tempo na } \\
\text { docência* }\end{array}$ & Modalidade $^{\star *}$ & Instituição *** \\
\hline & $\begin{array}{l}\text { Computação e Doutorado em Informática } \\
\text { na Educação. }\end{array}$ & & & \\
\hline $\operatorname{Esp}(7)$ & $\begin{array}{l}\text { Bacharelado em Química; Licenciatura em } \\
\text { Química; Licenciatura em Matemática; } \\
\text { Especialização em Docência do Ensino } \\
\text { Superior e Mestrado em Educação. }\end{array}$ & 13 anos. & Presencial. & Privada. \\
\hline Esp (8) & $\begin{array}{l}\text { Bacharelado em Psicologia; Especialização } \\
\text { em Administração e Desenvolvimento de } \\
\text { Recursos Humanos; Especialização em } \\
\text { Psicologia do Ensino e da Aprendizagem; } \\
\text { Especialização em Saúde do Trabalhador; } \\
\text { Mestrado em Administração e Doutorado } \\
\text { em Saúde Pública. }\end{array}$ & 23 anos. & Presencial. & Pública. \\
\hline Esp (9) & $\begin{array}{l}\text { Bacharelado em Medicina; Especialização } \\
\text { em Residência Médica; Mestrado em } \\
\text { Medicina e Doutorado em Medicina } \\
\text { Obstetrícia e Ginecologia. }\end{array}$ & 19 anos. & Presencial. & Pública. \\
\hline $\operatorname{Esp}(10)$ & $\begin{array}{l}\text { Bacharelado em Física; Mestrado em Física } \\
\text { e Doutorado em Física. }\end{array}$ & 29 anos. & Presencial. & Pública. \\
\hline Esp (11) & $\begin{array}{l}\text { Bacharelado em Administração; } \\
\text { Licenciatura em Pedagogia; Especialização } \\
\text { em Auditoria em Gestão Empresarial; } \\
\text { Especialização em Educação a Distância; } \\
\text { Mestrado em Engenharia e Gestão do } \\
\text { Conhecimento e Doutorado em Engenharia } \\
\text { e Gestão do Conhecimento. }\end{array}$ & 8 anos. & Presencial. & Privada. \\
\hline $\operatorname{Esp}(12)$ & $\begin{array}{l}\text { Licenciatura em Letras Português-Inglês e } \\
\text { suas Literaturas; Licenciatura em } \\
\text { Pedagogia; Mestrado em Educação e } \\
\text { Doutorado em Linguística e Língua } \\
\text { Portuguesa. }\end{array}$ & 30 anos. & Presencial. & Pública. \\
\hline Esp (13) & $\begin{array}{l}\text { Bacharelado em Jornalismo; Especialização } \\
\text { em Comunicação Empresarial e } \\
\text { Especialização em História e Culturas } \\
\text { Políticas. }\end{array}$ & 10 anos. & $\begin{array}{l}\text { Presencial, } \\
\text { EaD e Híbrido. }\end{array}$ & $\begin{array}{l}\text { Pública } \\
\text { Privada. }\end{array}$ \\
\hline Esp (14) & $\begin{array}{l}\text { Licenciatura em Matemática; Mestrado em } \\
\text { Geomática e Doutorado em Engenharia } \\
\text { Agrícola. }\end{array}$ & 8 anos. & $\begin{array}{l}\text { Presencial, } \\
\text { EaD e Híbrido. }\end{array}$ & Pública. \\
\hline
\end{tabular}

*Tempo na docência no ensino superior.

** Modalidade em que trabalha: ensino presencial; a distância ou ensino híbrido.

${ }^{* \star *}$ Fins lucrativos da instituição em que trabalha: ensino público ou privado.

Fonte: elaborado pelos autores com base nos dados da pesquisa (2020). 


\subsection{Discurso do Sujeito Coletivo}

Para a análise dos registros, utilizou-se como técnica do Discurso do Sujeito Coletivo (DSC), que é uma "[...] forma de conhecimento ou redução de variabilidade discursiva empírica, que implica um radical rompimento com a lógica quantitativo-classificatória na medida em que se busca resgatar o discurso como signo de conhecimento dos próprios discursos." (LEFÈVRE; LEFÈVRE, 2005, p. 19). Em concordância Duarte, Mamede e Andrade (2009, p. 623), complementam que o DSC é uma técnica de construção do pensamento coletivo que visa revelar como as pessoas pensam, atribuem sentidos e manifestam posicionamentos sobre determinado assunto. Trata-se de um compartilhamento de ideias dentro de um grupo social.

O DSC é composto por três figuras de linguagem: as expressões-chaves, as ideias centrais e as ancoragens. As expressões-chaves são extratos literais das falas dos professores que revelam a essência do discurso. As ideias centrais descrevem o "sentido de cada um dos discursos analisados e de cada conjunto homogêneo de $\mathrm{ECH}$, que vai dar nascimento, posteriormente ao DSC" (LEFÈVRE; LEFÈVRE, 2005, p. 17). A ancoragem, por sua vez "é uma manifestação linguística explícita de uma dada teoria, ou ideologia, ou crença que o autor do discurso professa e que, na qualidade de afirmação genérica, está sendo usada pelo enunciador para 'enquadrar' uma situação específica" (LEFÈVRE; LEFÈVRE, 2005, p. 17).

Para produzir um DSC, primeiramente realiza-se uma análise do material produzido e extrai-se, de cada declaração, as expressões-chave e suas correspondentes ideias centrais e/ou ancoragens. É a partir do conjunto dessas três figuras de linguagens de sentido igual ou semelhante que se produz o discurso que resume a fala do coletivo. Quando necessário, são utilizados conectores para darem coerência ao discurso, os quais, quando utilizados, serão sublinhados.

\section{4 \\ RESULTADOS: AS POTENCIALIDADES E DESAFIOS DO TRABALHO REMOTO}

Adaptar-se ao Ensino Remoto requer, entre outras questões, ter equipamentos e acesso à internet de qualidade que permitam trabalhar com as diferentes linguagens e recursos de texto, som, imagem, vídeos, tudo isso com multiusuários compartilhando espaços e tempos. Para além disso, o trabalho remoto conduz às buscas por novas formas de coordenação para as demandas educacionais que assumem outras dimensões nesse contexto, especialmente pelo fato da necessidade em ajustar a vida pessoal ao trabalho que adentrou os lares.

A pandemia trouxe diversas mudanças nas relações de trabalho, de consumo e sociais. Enquanto alguns setores viram seu faturamento cair abruptamente devido ao isolamento social, outros tiveram um consumo acelerado, a ponto de algumas empresas não conseguirem atender a demanda. Nesse nicho, estão as empresas de tecnologia e de serviços de telecomunicação que tiveram um crescimento para além do projetado. Fato esse, pode ser percebido pelo crescimento do uso da internet, já no início da pandemia no Brasil, em 19 de março. Wiziack e Soprana (2020) noticiariam que que em três dias de quarentena provocada pela onda da Covid-19 no país as operadoras de telefonia registraram um aumento médio de $40 \%$ no tráfego de internet banda larga fixa da rede folha de São Paulo; as principais operadoras de serviços de banda larga 
passaram a atender mais clientes em casa ao longo do dia e tiveram picos de consumo até $15 \%$ maiores. Nesse sentido, foi elaborado um discurso originado a partir da ancoragem "Potencialidades e desafios do trabalho remoto", que foi constituída das seguintes ideias centrais: acesso à internet, acesso à hardware, saúde x TIC, limitações de hardware e trabalho remoto. Tal discurso dá visibilidade às situações e percepções dos colaboradores do estudo acerca dos desafios e potencialidade do trabalho remoto (Quadro 3).

\section{Quadro 3: DSC: Potencialidades e desafios do trabalho remoto}

Não é uma dificuldade hoje, no ponto de vista estrutural, pessoal do professor, ele não ter internet. $O$ que acontece, como nós estamos na fronteira temos alguns picos de quedas, que são normais. $\mathrm{A}$ qualidade da minha internet é muito boa, nunca tive problema até hoje, então eu fiquei super tranquila nesse momento. Nós entramos na quarentena dia 14 de março e no dia 21 eu já estava com banda larga na minha residência justamente por conta das necessidades. Não é a mesma situação para alguns colegas que eu vejo quando a gente participa de algumas reuniões e eles começam: "Não estou ouvindo, tá falhando a imagem, estou só no celular" é uma realidade que não é só dos alunos. Pelo celular, e em geral essas pessoas têm problema, trava a tela, não consegue sair, então tem uma série de dificuldades também. Alguns professores, como eu, estavam abolindo a questão de computador, porque hoje a gente consegue fazer tudo pelo celular, eu estou falando contigo pelo meu celular, mas a gente recorre agora a ter que utilizar mais o computador, mas eu acho que mesmo com o celular a gente consegue acompanhar bastante. Eu tenho um Macbook que é da universidade, onde eu gosto da câmera e acho mais fácil fazer web conferência, e aqui do lado tem um outro computador, tenho um desktop que eu acho mais confortável para trabalhar. Meu computador é um laptop. O problema é que a bateria é viciada, se eu precisar ministrar uma palestra, eu preciso plugar na bateria e lá no quarto a internet fica um pouco lenta porque as paredes atuam como barreiras. A universidade não tem política de apoio, o que a gente tem alguns projetos que tinham recursos, então a gente acabava adquirindo notebooks, tablets, mas no tempo das vacas gordas, mas a grande maioria tem equipamento, talvez não o equipamento ideal, tu vê perguntas como: "como melhorar a qualidade do meu áudio, meu aluno não me enxerga bem." então tu vês que são questões não da internet, mas sim do equipamento. Então, ter o computador não quer dizer que tem o melhor computador. Eu já estou com bursite, fazendo fisioterapia, tenho que me lembrar de me sentar direito. A minha cadeira, quebrou o suporte e o acento começou a ficar inclinado e eu fui parar no hospital de tanta dor de cabeça, sem saber que era da cervical, foi muito sério, tive que usar até mesmo aquelas coleiras, então eu preparei a mesa, eu tenho suporte para o pé. Como a gente não tem filhos, os dois quartos são usados como escritório, então ele tem todo o equipamento dele, computador dele, eu tenho uma mesa própria uma cadeira própria, lá no meu quarto eu tenho um escritório melhor eu tenho uma questão confortável para trabalhar. Eu acho que o que mais me atrapalha, na verdade, são as atividades domésticas. A convivência é tranquila. Eu aviso quando tem a sala, ele me manda um Whatsapp e pergunta se estou no vídeo, "eu posso passar aí atrás?", às vezes minha esposa passa. Todo mundo foi pego de surpresa, acho que nenhum professor estava preparado para ter esse momento de ter seu lugar sossegado para gravar uma aula, acho que são raros os casos de professores que conseguem ter esse espaço mais reservado. A gente está em casa desde 13 de março, eu tenho que cozinhar, colocar a roupa na corda, isso me incomoda assim, essa interrupção. As pessoas não têm mais horário, esse maldito WhatsApp, esse maldito aplicativo. Alguns colegas dizem que isso gera atrito, porque tu tá em casa e não tá dando atenção um pro outro. Quando um casal tem um filho e os dois tem compromisso ao mesmo tempo, quem fica de olho no filho? Aqui a gente se olha, diz que vai gravar e o outro fica quieto, a gente acaba tendo que fazer um revezamento, qual a hora de cada um e já junta com a questão de espaço, acaba interferindo na agenda do outro. Eu tenho pet para atrapalhar, são os meus gatos. Eu procuro sempre trabalhar em horários em que eles estão mais calmos. Eu fico preocupada que aqui perto da minha casa está tendo obra então eventualmente eu estou na webcam e fica fazendo muito barulho para transmissão. Eu tenho avisado os colegas com quem eu trabalho que o meu turno acaba 6, 6 e meia. Eu estou tentando me policiar.

Tanto por questão de saúde, como por de descanso mesmo.

Fonte: elaborado pelos autores com base nos dados da pesquisa (2020). 
A partir da Teoria da Limitação Digital desenvolvida por Bellini, Giebelen e Casali (2010) que aborda as três dimensões da limitação digital percebemos fortemente as características da limitação de acesso. Essa limitação inclui má conexão com a internet, hardware e software inadequados, interfaces homem-computador complexas ou inflexíveis, ergonomia ruim do ambiente de uso - como móveis de escritório desconfortáveis, ruído, cheiro ruim e falta de privacidade -, tempo insuficiente para usar o computador e muitos outros fatores. Pelo DSC é possível perceber diversos relatos que exemplificam situações do cotidiano que vão ao encontro a tal limitação, especialmente no que se refere aos aspectos materiais.

Com o trabalho no formato remoto, outras configurações precisaram ser rearranjadas para estarem em consonância com a dinâmica familiar. Diversas são as variáveis que precisam ser consideradas no trabalho realizado em casa. Um estudo mostrou que muito antes da pandemia da Covid-19 o Brasil já apresentava um aumento expressivo nessa modalidade de trabalho. Gandra (2020) expõe o resultado de uma pesquisa que aponta, segundo a Confederação Nacional do Comércio (CNC), que a alternativa de trabalho remoto teve um aumento de cerca de $30 \%$. Tal modelo tem sido uma das principais opções para a manutenção das atividades laborais diante do isolamento social, pois é uma forma de evitar a contaminação no ambiente de trabalho. Contudo, faz-se urgente pensar: que estratégias as organizações têm desenvolvido para garantir a saúde dos colaboradores? Como fazer a transposição do modelo presencial para o modelo remoto? Como ofertar as condições de acesso, materiais, formação que garantam não só a produção, mas também o bem-estar das pessoas?

Essas são algumas questões que precisam ser pensadas quando se fala em mudar a lógica de trabalho em tempos de Covid19. Percebe-se com os relatos que as dificuldades de acesso sobressaem às de aspectos materiais - questões associadas à qualidade da infraestrutura -, pois incluem as limitações de acesso em relação aos aspectos sociais: conhecimento da ferramenta; tempo de experiência e domínio no uso; e participação em atividades que estimulam o uso da ferramenta. As dificuldades referentes aos aspectos sociais talvez sejam as mais desafiadoras.

Outro ponto que tem surgido de forma recorrente é a extrapolação da carga horária de trabalho. Estudos mostram que a produtividade na modalidade do trabalho remoto é maior; por outro lado, as pessoas trabalham muito mais, pois a desvinculação com o espaço físico do trabalho faz com que elas permaneçam mais horas conectadas e, por consequência, trabalhando excessivamente, em alguns casos. O relato evidencia tal fato: "[...] tenho avisado os colegas com quem eu trabalho que o meu turno acaba 6, 6 e meia. Eu estou tentando me policiar. Tanto por questão de saúde, como por de descanso mesmo".

O artigo intitulado Com o coronavírus, jornada de trabalho em casa aumenta 3 horas, publicado na revista Exame (BLOOMBERG, 2020), aponta que um provedor de internet americano, Sufshark, observou picos de uso da meia-noite às 3 horas da madrugada que não estavam presentes antes do surto da Covid-19. Essa mesma reportagem destaca que uma startup de tecnologia com sede em Toronto apontou que seus 15 funcionários estão trabalhando, em média, 12 horas por dia - 3 horas acima das 9 horas pré-pandemia - ressaltando que esse aumento se dá devido a mudanças de hábito das pessoas, uma vez que conseguem estar conectadas mais cedo, 
pois não há o período de deslocamento, e também pela privação da vida social, o que deixa as pessoas mais disponíveis para atender as questões relacionadas ao trabalho.

Referente ao fato de que as falhas de conexão são habituais e que isso já faz parte do cotidiano dos professores, uma pesquisa do Datafolha, divulgada pelo Gazeta do Povo (2020) apresenta estimativas de que pelo menos 4,8 milhões entre estudantes e professores em todo o Brasil não têm acesso à internet em suas residências, enquanto outros milhões têm acesso precário ou sofrem com falta de equipamentos. A pesquisa ainda investigou o cotidiano de estudos em casa de alunos e professores das redes públicas - municipais e estaduais no Brasil. A parcela de estudantes e docentes desmotivados, subiu de $46 \%$ em maio para $51 \%$ em julho. Da mesma forma, aumentaram as dificuldades para manter a rotina. Por esse motivo, um número maior de pais e professores teme que os estudantes desistam da escola - o percentual foi de $31 \%$ para 38\%. Mesmo diante do fato de que o acesso à internet esteja crescendo é preciso levar em consideração que esse ainda não é um problema vencido pelos muitos dos atores educacionais e estudantes.

Alguns professores relatam problemas como não conseguir ouvir o áudio, ver a imagem dos colegas etc. Sobre isso, Cafardo (2020) confirma que essas dificuldades têm sido uma constante para os professores que estão tentando se adaptar. A autora aponta em um estudo que quase $90 \%$ dos docentes nunca tinham tido qualquer experiência com o Ensino à distância, e que 55\% não receberam, até agora, suporte ou treinamento para atuar de maneira não presencial. Sem orientação clara, os profissionais têm criado as próprias atividades. Ainda nessa pesquisa, 83\% afirmaram se comunicar pelo WhatsApp com as famílias dos alunos em vez de usar ferramentas pedagógicas das escolas ou redes. Em escolas particulares, o WhatsApp é menos comum: 56\% disseram usar o aplicativo de mensagens para se comunicar com o aluno. A comunicação por meio de plataformas da escola é a mais frequente; no entanto, o sentimento de despreparo desses professores diante do desafio de ensinar on-line parece ser o mesmo. Para esses docentes, as situações foram impostas de um dia para o outro com o isolamento, e entendem que ninguém teve tempo de se preparar.

Sobre o uso dos artefatos tecnológicos, enquanto alguns têm melhores computadores, outros professores estão utilizando seus celulares para dar conta do trabalho. Carla (2020) apresenta dados de uma pesquisa feita no Distrito Federal (DF) que dialogam com esses resultados. A pesquisa realizada com professores e orientadores educacionais constatou que $22,25 \%$ destes não têm computadores. Quando desmembrados os dois segmentos da categoria do magistério público, a autora mostrou que, dos 35 mil professores da rede pública do DF, um total de 23 mil é de professores que estão em sala de aula e, entre estes regentes, 21,97\% não têm computador, ou seja, cinco mil professores regentes não têm computador e não têm como executar suas atividades pedagógicas. Esses números de 35 mil professores e 1.132 orientadores educacionais estão registrados na Nota Técnica nº 09 (NT09), da Subsecretaria de Gestão de Pessoas (SuGeP), da Secretaria de Estado da Educação do DF (SEEDF). Tal categoria é formada, ao todo, por 36.132 trabalhadores do magistério público. Dessa forma, a pesquisa constatou que, dentre esses 36.132, uma soma de 8 mil educadores não tem computador em casa.

Sobre as questões ergonômicas, como não ter cadeira, mesa e ambiente apropriados para a execução de trabalho, resultando até mesmo no desenvolvimento de doenças e a necessidade 
de apoio fisioterapêutico, percebe-se que essas dificuldades não são novas e apenas relacionadas ao trabalho remoto por causa da Covid-19. Rocha (2019) já apontava que os docentes são expostos aos riscos ambientais, e que é fundamental a elaboração do Programa de Controle Médico de Saúde Ocupacional (CMSO) e do Programa de Prevenção de Riscos Ambientais (PPRA) nas Instituições acadêmicas para prevenção da saúde e qualidade de vida desses professores. Outro dado apresentado pela autora é o fato de que com o passar dos anos de trabalho em condições não favoráveis, cerca de $5 \%$ dos docentes acabam sendo afastados e/ou readaptados. Destes, mais da metade terão queda significativa na qualidade de vida devido às dores crônicas. Essas dores são causadas pela falta de estrutura adequada no ambiente de trabalho, como apontada nesse estudo.

Ao relacionar as dificuldades em organizar a rotina e o trabalho remoto como limitadores responsáveis por atrapalhar as aulas on-line, o portal FolhaVitoria.com (2020) apresentou os resultados de pesquisa realizada com estudantes e professores de todo o Brasil matriculados em instituições públicas e privadas. Tais resultados apontaram que a falta de organização da rotina para estudar de forma on-line se apresenta como limitador para o Ensino não presencial nesse período de quarentena. Os dados da pesquisa mostraram ainda que $45 \%$ dos entrevistados disseram ter dificuldades e, por isso, acabam participando apenas em parte das aulas on-line (23\%), enquanto outros $6 \%$ relataram não participar de nenhuma aula on-line. Entre demais motivos apresentados pelos entrevistados, está a dificuldade em conciliar as aulas com o home office (25\%), bem como as tarefas domésticas (23\%).

0 trabalho remoto afeta as experiências familiares no lar. Os entrevistados apontaram que essa nova atividade dentro de suas casas pode até mesmo restringir de certa forma a liberdade dos membros da família. Assim, percebe-se que essa é uma questão que já vem sendo apontada na literatura. Sullivan (2000) relata que o trabalho remoto deveria ser inserido de forma paulatina no ambiente familiar, a fim de permitir a adaptação dos outros membros, considerando as experiências e necessidades da família à medida que esse trabalho vai acontecendo. Ainda nesse sentido, o autor apontou que as famílias podem responder de formas diferentes: enquanto alguns talvez vejam como algo bom, outros podem pender para as desvantagens.

Por fim, é importante destacar as dificuldades apresentadas pelos professores em gerenciar suas agendas, bem como a constante necessidade de estar on-line e dar respostas rápidas, uma vez que isso ficou ainda mais evidente durante o home office, especialmente para os professores (OLIVEIRA, 2020). Para a autora, o excesso de atividades é desgastante tanto para o estudante como para o professor. Enquanto o estudante fica nervoso e preocupado com a entrega das tarefas, e pode não aprender o conteúdo, o docente, que normalmente leciona em mais de uma turma, acaba tendo que dedicar mais tempo de trabalho para preparar as aulas, criar atividades e corrigi-las. Além disso, a autora aponta que as instituições de ensino vão precisar definir planejamentos para as atividades dos professores e articular a atuação deles.

\section{CONSIDERAÇÕES FINAIS}

A fim de entender as potencialidades da utilização do trabalho remoto e as limitações de acesso desse período, foi construído o Discurso do Sujeito Coletivo. 
Percebeu-se que as falhas de conexão com internet são habituais e que isso já faz parte do cotidiano dos professores. Nesse sentido, alguns relataram problemas que parecem ser de configuração, como não conseguir ouvir o áudio, ver a imagem dos colegas e outros. Diversas instituições estão investindo em alguma forma de mitigar esse problema, mas é algo que ainda exige atenção, uma vez que a banda de internet dos professores pode não ser suficiente. Válido destacar que essa não deve ser uma obrigação do professor, dado que a instituição precisa prover os meios para a execução de seu trabalho.

A utilização do artefato também apareceu nos relatos. Enquanto uns têm melhores computadores, como o Macbook, outros professores estão utilizando seus celulares para dar conta da demanda de trabalho. Alguns expuseram que estavam em uma transição para usar todas as ferramentas diretamente no celular, mas fizeram um retorno nesse sentido e voltaram a usar os computadores. É certo que os aparelhos smartphones têm apresentado configurações robustas as quais permitem que muitas atividades sejam executadas, mesmo com a limitação do tamanho da tela. Todavia, os melhores aparelhos ainda apresentam valores, muitas vezes, acima daquilo possível de ser pago, principalmente em uma emergência e sem planejamento, como foi o imposto pela pandemia. Mais uma vez, retoma-se o já discutido: essa obrigação não pode ser do professor, mas sim da instituição que o emprega.

Além disso, foi relatado a falta de suporte em uma questão física, como não ter cadeira, mesa e ambiente apropriados para a execução do trabalho, resultando até mesmo no desenvolvimento de doenças e na necessidade de apoio fisioterapêutico. Uma breve busca na internet mostra shoppings de e-commerce vendendo "kit de trabalho remoto" com escrivaninha, cadeira e luminária, em uma intenção de aumentar suas vendas. Nenhuma crítica, tendo em vista do lucro ser o objetivo de empresas de varejo. No entanto, aquilo que agora aparece, e que antes nem era pensado, traz à baila o fato de que muitas pessoas não têm esse espaço apropriado para trabalhar em casa. Muitos professores estão dando aula sentados à mesa de jantar, no sofá da sala ou mesmo na cama. Apenas atesta-se: falta estrutura para trabalho remoto na casa dos professores.

Questões relacionadas ao gerenciamento de atividades domésticas e o trabalho remoto aparecem como problemas, pois estar em casa significa um acúmulo de atividades que antes não tinham tanta frequência, como, por exemplo, ter de se preparar almoço e lavar a louça em vez de fazer essa refeição em um restaurante. Assim como alunos podem assistir aula "lavando a louça" ou "preparando café", quantos professores estão tão sobrecarregados de reuniões que a única alternativa é "ouvir a reunião" enquanto "coloca a roupa para lavar"? Imperativo que seja feito um planejamento adequado para que os docentes possam se organizar e conciliar suas agendas.

Ainda nesse sentido, há um relato de que o trabalho remoto possa estar atrapalhando a convivência doméstica, uma vez que os professores acabam, por outros membros da família, restritos em sua liberdade, como o fato de ter que se fazer silêncio ou não andar pela casa, pois se está em alguma reunião ou ministrando alguma aula. Enquanto algumas famílias podem se sentir invadidas, outras podem pensar nisso como algo positivo, ao permitir a proximidade entre as pessoas que não se viam tanto antes da pandemia. Embora pesquisas sobre trabalho remoto estejam abordando temas como autonomia, flexibilidade, produtividade, utilização do espaço, balanço trabalho-família, entre outros, as percepções, experiências e perspectivas daqueles que, 
inevitavelmente, são envolvidos no processo de trabalho remoto também precisam ser abordadas pelos pesquisadores.

Por fim, a questão de procurar fazer um ajuste de agenda e trabalhar em um horário em que se estaria trabalhando no ambiente físico. Agendar reuniões e aulas nesse período e buscar formas de gerenciar a incessante cobrança por rápidas respostas nos aplicativos de mensagens instantâneas, como o Whatsapp. É importante destacar o adjetivo dado ao aplicativo e que foi colocado no DSC: "o maldito" Whatsapp. Com certeza, o mensageiro revolucionou a forma como nos comunicamos tornando tudo dinâmico e instantâneo. Todavia, "estar on-line" não precisa necessariamente estar disponível para o trabalho, uma vez que o professor pode estar fazendo qualquer outra coisa no momento. Será necessário voltar aos primórdios da comunicação da internet e trabalhar conceitos de netiqueta.

Como limitação, essa pesquisa apresenta o fato de que as entrevistas foram executadas em um momento específico, em torno de três meses após o início do período de trabalho remoto. Sugere-se para futuras pesquisas um novo levantamento de dados com os mesmos entrevistados a fim de se perceber novas limitações ou mesmo a forma como estão lidando com as limitações já apontadas eles mesmos.

\section{REFERÊNCIAS}

AGARWAL, R; ANIMESH, A.; PRASAD, K. Social interactions and the "digital divide": Explaining variations in Internet use. Information Systems Research, v. 20, n. 2, p. 277-294, 2009.

ARRUDA, E. P. Emergency remote education: elements for public policies in Brazilian education in Covid19 times. EmRede: Revista de Educação a Distância, v. 7, n. 1, p. 257-275, 2020.

BELLINI, C. G. P. The ABCs of effectiveness in the digital society. Communications of the ACM, v. 61, n. 7, p. 84-91, 2018.

BELLINI, C. G. P.; GIEBELEN, E.; CASALI, R. R. B. Limitações digitais. Informação \& Sociedade: Estudos, v. 20, n. 2, p. 25-35, 2010.

BELLINI, C. G. P. et al. Self-efficacy and anxiety of digital natives in face of compulsory computer-mediated tasks: A study about digital capabilities and limitations. Computers in Human Behavior, v. 59, n. 1, p. 49$57,2016$.

BELLINI, C. G. P. et al. Limitações digitais: Evidências teóricas preliminares. Análise-Revista de Administração da PUCRS, v. 23, n. 1, p. 58-70, 2012.

CARLA, M. GDF quer fazer EaD com 127 mil estudantes sem Internet e 8 mil professores sem computador. Portal SINPRODF, 03 jun. 2020. Disponível em: https://www.sinprodf.org.br/gdf-quer-fazer-ead-com-127mil-estudantes-sem-internet-e-8-mil-professores-sem-computador/. Acesso em: 07 out. 2020.

CHAGAS, E. DataSenado: quase 20 milhões de alunos deixaram de ter aulas durante pandemia. Portal Senado Notícias, 12 ago. 2020. Disponível em:

https://www12.senado.leg.br/noticias/materias/2020/08/12/datasenado-quase-20-milhoes-de-alunosdeixaram-de-ter-aulas-durante-pandemia. Acesso em: 04 out. 2020. 
DUARTE, S. J. H.; MAMEDE, M. V.; ANDRADE, S. M. O. Opções Teórico Metodológicas em Pesquisas Qualitativas: Representações Sociais e Discurso do Sujeito Coletivo. Revista Saúde e Sociedade - USP, v. 18, n. 4, p. 620-626, 2009.

DWIVEDI, Y.; IRANI, Z. Understanding the adopters and non-adopters of broadband. Communications of the ACM, v. 52, n. 1, p. 122-125, 2009.

BLOOMBERG. Com coronavírus, jornada de trabalho em casa aumenta 3h. Você também?. Exame, 26 abr. 2020. Disponível em: https://exame.com/carreira/trabalhar-em-casa-na-era-coronavirus-jornadaextra-de-3-horas/. Acesso em: 04 out. 2020.

FOLHA VITÓRIA. Dificuldade em organizar a rotina e home office são responsáveis por atrapalhar aulas on-line. Portal Folha Vitória. 29 set. 2020. Disponível em:

https://www.folhavitoria.com.br/geral/noticia/09/2020/dificuldade-em-organizar-a-rotina-e-home-officesao-responsaveis-por-atrapalhar-aulas-online. Acesso em: 04 out. 2020.

GANDRA, A. Empresas adotam home-office por conta do Coronavírus. Agência Brasil. 07 mar. 2020. Disponível em: https://agenciabrasil.ebc.com.br/saude/noticia/2020-03/empresas-adotam-home-officepor-conta-do-coronavirus. Acesso em: 04 out. 2020.

GAZETA DO POVO. Eles não têm condições de acompanhar aulas on-line. E se preocupam com o futuro. Gazeta do povo. 31 ago. 2020. Disponível em: https://www.gazetadopovo.com.br/educacao/alunos-semcondicoes-aulas-online/. Acesso em: 04 out. 2020.

GOMES, K. A. Controvérsias na política de $\mathbf{2 0} \%$ a distância: a caixa-preta. Tese (Dourorado em Educação). Universidade Federal de Santa Catarina, Florianópolis, 2018.

HERNANDES, P. R. A Universidade Aberta do Brasil e a democratização do Ensino Superior público.

Ensaio: Avaliação e Políticas Públicas em Educação, v. 25, n. 95, p. 283-307, 2017.

HODGES, C. et al. The difference between emergency remote teaching and on-line learning. Educause Review. 27 mar. 2020. Disponível em: https://er.educause.edu/articles/2020/3/the-difference-betweenemergency-remote-teaching-and-online-learning. Acesso em: 04 out. 2020.

INSTITUTO PENÍNSULA. Sentimento e percepção dos professores brasileiros nos diferentes estágios do Coronavírus no Brasil. Instituto Península. 25 mar. 2020. Disponível em:

https://institutopeninsula.org.br/wp-content/uploads/2020/03/Pulso-Covid-19_-Instituto-

Peni\%CC\%81nsula.pdf. Acesso em: 04 out. 2020.

KLECUN, E. Bringing lost sheep into the fold: Questioning the discourse of the digital divide. Information Technology \& People, v. 21, n. 3, p. 267-282, 2008.

LEFÈVRE, F.; LEFÈVRE, A. M. C. Discurso do Sujeito Coletivo: um novo enfoque em pesquisa qualiquantitativa (Desdobramentos). 2. ed. Caxias do Sul: Educs, 2005.

MAIA, C.; MATTAR, J. ABC da EaD: a educação a distância hoje. Pearson Prentice Hall, 2008.

MARIVATE, V.; COMBRINK, H. MvE. Framework for sharing publicly available data to inform the COVID-19 Outbreak in Africa: A South African case study. Computer Science. No prelo, 2020.

MIRANDA, G. L. The limits and possibilities of ict in education. Sísifo: Revista de Ciências da Educação, Lisboa, n. 3, p. 41-50, 2007. 
MORAN, J. Mudando a educação com metodologias ativas. Coleção Mídias Contemporâneas:

Convergências midiáticas, educação e cidadania: aproximações jovens, v. 2, n. 1, p. 15- 31, 2015.

NICOLA, M. et al. Evidence based management guideline for the COVID-19 pandemic: review article. International Journal of Surgery, v. 77, n. 1, p. 206-216, 2020.

NOVELLO, T. P.; PEREIRA JUNIOR, E. F. Z.; RIBEIRO, N. F. Ambientes virtuais de aprendizagem: limitações digitais dos professores em época de pandemia do Covid-19. In: SIMPÓSIO NACIONAL DE ESTRATÉGIASE MULTIDEBATES DA EDUCAÇÃO, 1., 2020. Anais [...], On-line: 2020.

OLIVEIRA, D. Burnout: quarentena e excesso de tarefas leva professores ao esgotamento. Desafios da educação. 19 ago. 2020. Disponível em: https://desafiosdaeducacao.grupoa.com.br/burnoutesgotamento-professores/. Acesso em: 07 out. 2020.

PEREIRA JUNIOR, E. F. Z.; PAES, K. D.; RIBEIRO, N. F. Background pessoal do professor: análise bibliométrica da produção científica mundial. Revista Eletrônica Científica Da UERGS, v. 6, n. 3, p. 278288, 2020.

PEREIRA JUNIOR, E. F. Z.; SCHROEDER, E. A.; DOLCI, D. B. Limitações digitais na utilização da ferramenta trello para o planejamento estratégico: um estudo de caso. In: MOSTRA DE PRODUÇÃO ACADÊMICA, 9., 2018. Anais eletrônicos, Rio Grande: 2018.

PEREIRA JUNIOR, E. F. Z.; SCHROEDER, E. A.; DOLCI, D. B. Limitações digitais, causas e consequências na efetividade do uso do site trello no planejamento estratégico de uma secretaria de Educação a Distância de uma universidade federal. EmRede-Revista de Educação a Distância, v. 6, n. 1, p. 69-85, 2019.

RAPANTA, C. et al. On-line university teaching during and after the Covid-19 crisis: Refocusing teacher presence and learning activity. Postdigital Science and Education, v. 2, n. 3, p. 923-945, 2020.

ROCHA, R. G. Análise das condições ergonômicas dos professores no ambiente laboral: um estudo de caso. Brasil Escola. 01 out. 2019. Disponível em: https://meuartigo.brasilescola.uol.com.br/doencassaude/analise-das-condicoes-ergonomicas-dos-professores-no-ambiente.htm. Acesso em: 07 out. 2020.

SPINELLI, A.; PELLINO, G. Covid-19 pandemic: perspectives on an unfolding crisis. The British journal of surgery, v. 107, n. 7, p. 785-787, 2020.

SULLIVAN, C. Space and the intersection of work and family in homeworking households. Community, Work \& Family, v. 3, n. 2, p. 185-204, 2000.

TOKARNIA, M. Um em cada 4 brasileiros não tem acesso à internet, mostra pesquisa. Agência Brasil. 29 abr. 2020. Disponível em: https://agenciabrasil.ebc.com.br/economia/noticia/2020-04/um-em-cadaquatro-brasileiros-nao-tem-acesso-internet. Acesso em: 04 out. 2020.

VAN DIJK, J.; HACKER, K. The digital divide as a complex and dynamic phenomenon. The information society, v. 19, n. 4, p. 315-326, 2003.

WILLIS, S.; TRANTER, B. Beyond the "digital divide": Internet diffusion and inequality in Australia. Journal of Sociology, v. 42, n. 1, p. 43-59, 2006.

WIZIACK, J.; SOPRANA, P. Em três dias de quarentena, consumo de internet fixa sobe $\mathbf{4 0} \%$. Folha, 19 mar. 2020. Disponível em: https://www1.folha.uol.com.br/mercado/2020/03/em-tres-dias-de-quarentenaconsumo-das-redes-de-telefonia-subiu-40.shtml. Acesso em: 04 out. 2020. 